\title{
Dataset Paper \\ Butterfly Species List for Selected West Albertine Rift Forests
}

\author{
Patrice Kasangaki, ${ }^{1}$ Anne M. Akol, ${ }^{2}$ and Gilbert Isabirye Basuta ${ }^{2}$ \\ ${ }^{1}$ National Livestock Resources Research Institute (NaLIRRI), P.O. Box 96, Tororo, Uganda \\ ${ }^{2}$ Department of Biological Sciences, Makerere University, P.O. Box 7062, Kampala, Uganda \\ Correspondence should be addressed to Patrice Kasangaki; pkasangaki2005@yahoo.com
}

Received 1 May 2012; Accepted 10 June 2012

Academic Editors: M. Skoracki and P. Tryjanowski

Copyright (c) 2013 Patrice Kasangaki et al. This is an open access article distributed under the Creative Commons Attribution License, which permits unrestricted use, distribution, and reproduction in any medium, provided the original work is properly cited.

This dataset gives details on a study which was conducted in seventeen forests in western Uganda (Albertine region) between 1993 and 1995. Different methods were used to sample butterflies from these forests. A total of 630 butterfly species were collected in 5 main families. Key characteristics of the forests were recorded, and these were found to influence the butterfly species richness of the forests.

\section{Introduction}

Butterflies are known to respond to environmental changes, and there have been considerable amounts of data collected on how particular species contend with alteration in land use $[1,2]$ and thus may play a valuable role in ecological monitoring [3].

In Uganda, some 1245 species of butterflies have been recorded [4] from a variety of habitats, and it is thus feasible to evaluate the butterfly fauna of the region as well as derive reasonably accurate comparisons of sites and subsequently identify conservation requirements. This dataset paper examines the butterfly species diversity and distribution in selected West Albertine Rift Forests.

\section{Methodology}

This study was based on secondary data collected by the former Forest Department, now National Forestry Authority (NFA), over a period of three years from January 1993 to December 1995 as part of a National Forestry Biodiversity in seventeen forests (see [5]). For the purposes of this study, West Albertine Rift Forests were taken to be those found within the geographical boundaries north of Lake Albert between Arua and Pakwach (West Nile) and the forests of western Uganda (Figure 1).
Twelve fine-mesh cylindrical traps (approximately $70 \times$ $40 \mathrm{~cm}$ diameter) were set at a range of heights from 1 to $10 \mathrm{~m}$ above ground level for the duration of the survey. A variety of baits including fermenting banana, dog feces, chicken offal, urine, and locally distilled alcohol were used in the traps. Traps were checked regularly, and representative specimens of each species were collected. For those species not usually attracted to traps, sweep netting was carried out daily in a range of habitat types within the forests. The average sampling efforts for each forest were measured in terms of man-days and the different forests' characteristics recorded (Table 1). Secondary data on the ecological attributes of interest (forest size, altitude, plant species richness, rainfall, and temperature) and the human activities in the forests recorded by the Forest Department were used to generate Table 1 . We made visits to the forests in order to determine the levels of human activities in them. It was these activities which were regarded as forest disturbance. The activities considered for the purpose of this study were lumbering, agriculture (crop and livestock), hunting, charcoal burning, and settlement. These were arbitrarily scored within a range of $0-5$, where 0 is nonexistent and 5 is the highest activity present. All the collected specimens were put in papers with their wing folded on the back and later identified. The species list was compiled as shown in Dataset Item 1 (Table). 
TABLE 1: Key characteristic of the study forests.

\begin{tabular}{|c|c|c|c|c|c|c|c|c|}
\hline Number & Forests & $\begin{array}{l}\text { Forest Size } \\
\left(\mathrm{Km}^{2}\right)\end{array}$ & $\begin{array}{l}\text { Average Altitude } \\
\text { (Masl) }\end{array}$ & $\begin{array}{l}\text { Number of } \\
\text { Plant spp. }\end{array}$ & $\begin{array}{l}\text { Disturbace } \\
\text { Level }\end{array}$ & $\begin{array}{c}\text { Mean Annual } \\
\text { Rainfall } \\
(\mathrm{mm})\end{array}$ & $\begin{array}{c}\text { Mean Annual } \\
\text { Temperature } \\
\left({ }^{\circ} \mathrm{C}\right)\end{array}$ & $\begin{array}{c}\text { Number of } \\
\text { Butterfly Species }\end{array}$ \\
\hline 1 & $\begin{array}{c}\text { Kalinzu- } \\
\text { Maramagambo }\end{array}$ & 854 & 1380 & 414 & 13 & 1275 & 21.25 & 227 \\
\hline 2 & Itwara & 87 & 1365 & 256 & 12 & 1325 & 21 & 119 \\
\hline 3 & Bugoma & 401 & 1142.5 & 527 & 16 & 1225 & 22.7 & 278 \\
\hline 4 & Kisangi & 54 & 1007 & 98 & 8 & 1350 & 21.5 & 41 \\
\hline 5 & Budongo & 793 & 985 & 127 & 16 & 1325 & 22.3 & 254 \\
\hline 6 & Rwenzori & 996 & 3404.5 & 195 & 5 & 1250 & 21.5 & 78 \\
\hline 7 & Echuya & 34 & 2420 & 127 & 7 & 1650 & 17.25 & 54 \\
\hline 8 & Mafuga & 34 & 2420 & 115 & 9 & 1650 & 17.25 & 32 \\
\hline 9 & Kagombe & 113 & 1242 & 209 & 12 & 1350 & 21.3 & 190 \\
\hline 10 & Matiri & 54 & 1363.5 & 115 & 6 & 1350 & 21.3 & 98 \\
\hline 11 & Kitechura & 53 & 1280.5 & 114 & 7 & 1325 & 19.75 & 114 \\
\hline 12 & Kasyoha-Kitomi & 399 & 1555.5 & 376 & 14 & 1325 & 21.25 & 235 \\
\hline 13 & Semliki & 219 & 715 & 339 & 5 & 1350 & 20.5 & 309 \\
\hline 14 & Kibale & 564 & 1350 & 351 & 5 & 1650 & 17.25 & 220 \\
\hline 15 & Bwindi & 231 & 1898.5 & 324 & 5 & 1440 & 17.25 & 162 \\
\hline 16 & Mt. Kei & 384 & 1123.5 & 229 & 13 & 1250 & 23 & 126 \\
\hline 17 & Era & 74 & 945 & 261 & 13 & 1250 & 23 & 56 \\
\hline
\end{tabular}

\section{Dataset Description}

The dataset associated with this Dataset Paper consists of one item which is described as follows.

Dataset Item 1 (Table). Species list for the different forests. Data presented in this table were based on the presence (1) or absence ( 0 ) of a butterfly species and used to establish the similarity among the forests. The species list was generated by recording representatives of each species. The number of individuals per species was not considered.

Column 1: Butterfly Family

Column 2: Butterfly Subfamily

Column 3: Butterfly Species

Column 4: Kalinzu-Maramagambo

Column 5: Itwara

Column 6: Bugoma

Column 7: Kisangi

Column 8: Budongo

Column 9: Rwenzori

Column 10: Echuya

Column 11: Mafuga

Column 12: Kagombe

Column 13: Matiri

Column 14: Kitechura

Column 15: Kasyoha-Kitomi
Column 16: Semliki

Column 17: Kibale

Column 18: Bwindi

Column 19: Mt. Kei

Column 20: Era

\section{Concluding Remarks}

This dataset paper was developed in order to come up with butterfly species list which can be used in the analysis of different factors responsible for their diversity and distribution. Although Era and Mt. Kei forest reserves are not part of the Albertine Rift Forests, they were included for comparison with those within the rift.

\section{Dataset Availability}

The dataset associated with this Dataset Paper is dedicated to the public domain using the CCO waiver and is available at http://dx.doi.org/10.7167/2013/451461/dataset.

\section{Disclosure}

The data presented here were generated from secondary data and information collected by the former Forest Department (now National Forestry Authority, NFA). The samples were collected during a National Biodiversity Assessment between January 1993 and December 1995 by a team of six rangers supervised by Dr. Tim Davenport. 


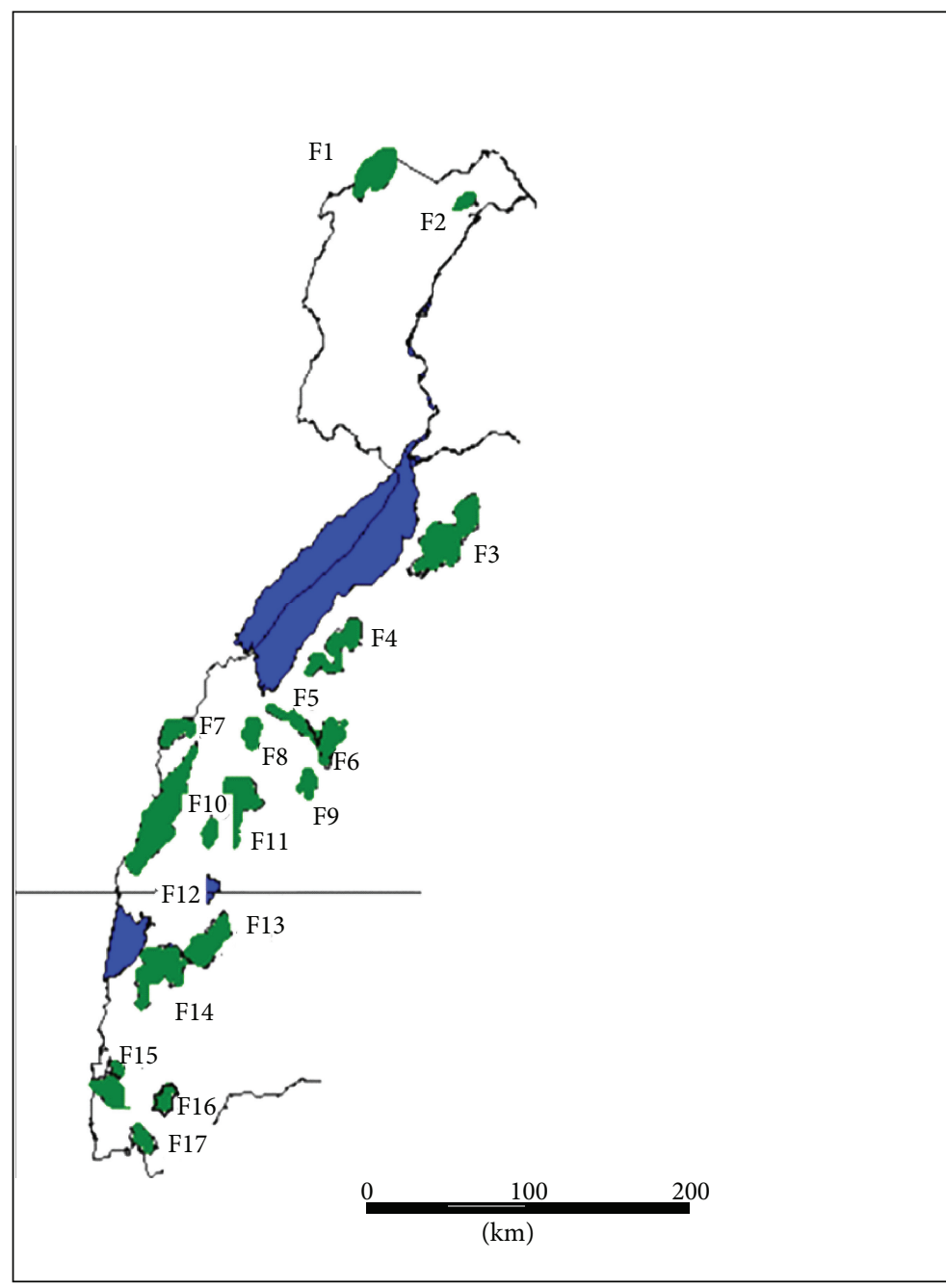

$\begin{array}{lll}\text { F1 }=\text { Mt.Kei FR } & \text { F7 }=\text { Semliki NP } & \text { F13 }=\text { Kashyoha-Kitomi FR } \\ \text { F2 }=\text { Era FR } & \text { F8 }=\text { Itwara FR } & \text { F14 }=\text { Kalinzu-Maramagambo FR } \\ \text { F3 }=\text { Budongo FR } & \text { F9 }=\text { Matiri FR } & \text { F15 }=\text { Bwindi Impenetrable NP } \\ \text { F4 }=\text { Bugoma FR } & \text { F10 }=\text { Kisangi FR } & \text { F16 }=\text { Mafuga FR } \\ \text { F5 }=\text { Kagombe FR } & \text { F11 = Kibale NP } & \text { F17 }=\text { Echuya FR } \\ \text { F6 }=\text { Kitechura FR } & \text { F12 }=\text { Rwenzori NP } & \end{array}$

Figure 1: Forests of the WARFs whose butterfly fauna was studied (adopted from [5]). NP: National Park; FR: Forest Reserve.

\section{Acknowledgments}

The authors extend their sincere gratitude to NUFU Linkage, Makerere University (Biodiversity Project), for the financial support extended to them which enabled them assemble these data and come up with this piece of work. They are also grateful to the National Forest Authority (formerly the Forest Department) for making the butterfly samples which were used for this study available. They are very grateful to Dr. Tim Davenport who led the team of rangers who collected the butterfly samples which were used here. Last but not least, they are thankful to Dr. Robert Kityo, the Curator of
Makerere University Museum, for all the support he rendered to them during data assembling.

\section{References}

[1] N. Carder and L. Tindimubona, Butterflies of Uganda: A Field Guide to Butterflies and Silk Moths from the Collection of the Uganda Society, Uganda Wildlife Society, 2002.

[2] T. R. B. Davenport, Endemic Butterflies of the Albertine Rift-An Annotated Checklist, The Wildlife Conservation Society, Mbeya, Tanzania, 2002. 
[3] Gretchen C. Daily and Paul R. Ehrlich, "Preservation of biodiversity in small rainforest patches: rapid evaluations using butterfly trapping," Biodiversity and Conservation, vol. 4, no. 1, pp. 35-55, 1995.

[4] T. R. B. Davenport, The Butterflies of Uganda-An Annotated Checklist, Uganda Forest Department, Kampala, Uganda, 2003.

[5] P. C. Howard, T. R. B. Davenport, and M. Baltzer, Eds., Forest Biodiversity Reports, vol. 1-33, Forest Department, Kampala, Uganda, 1996. 

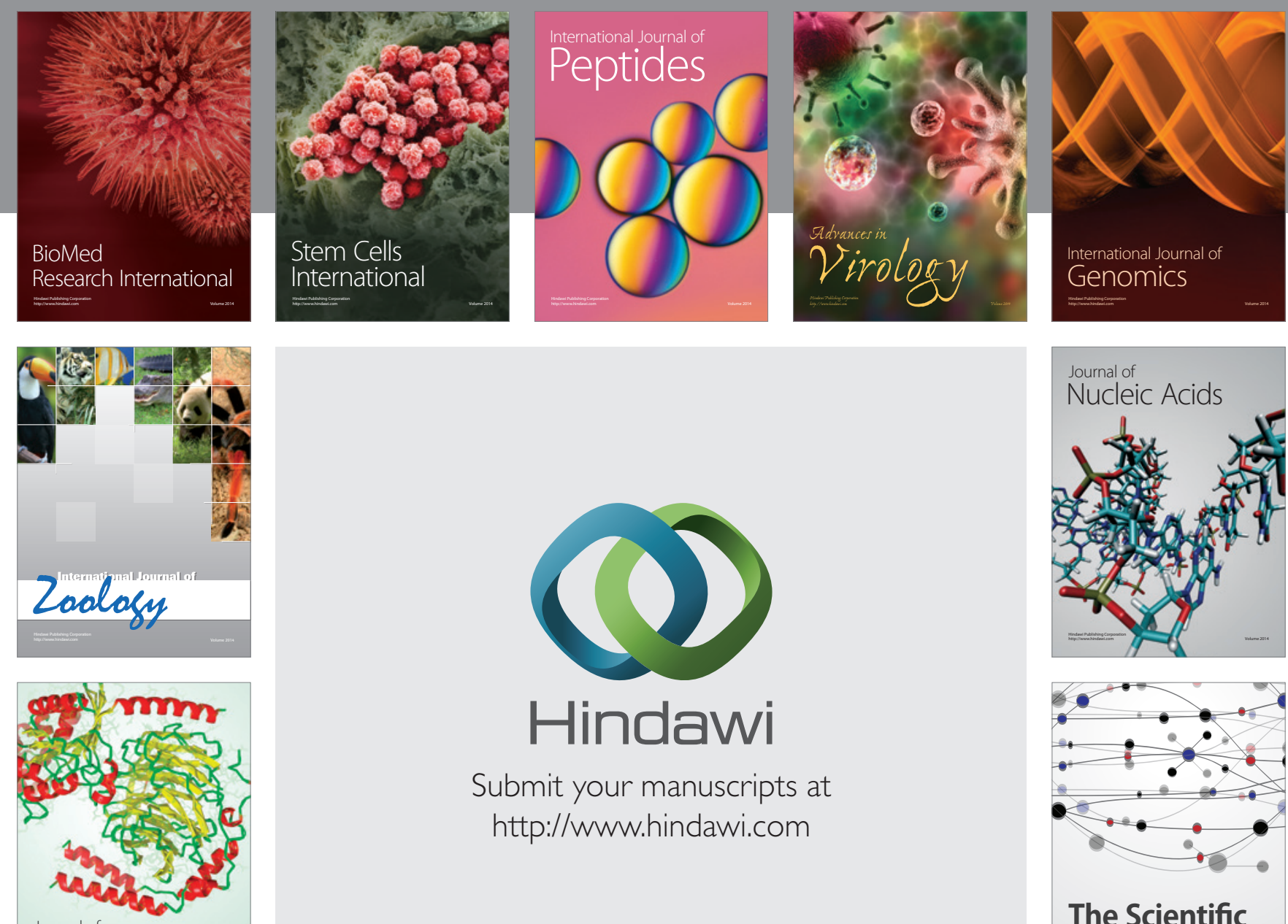

Submit your manuscripts at

http://www.hindawi.com

Journal of
Signal Transduction
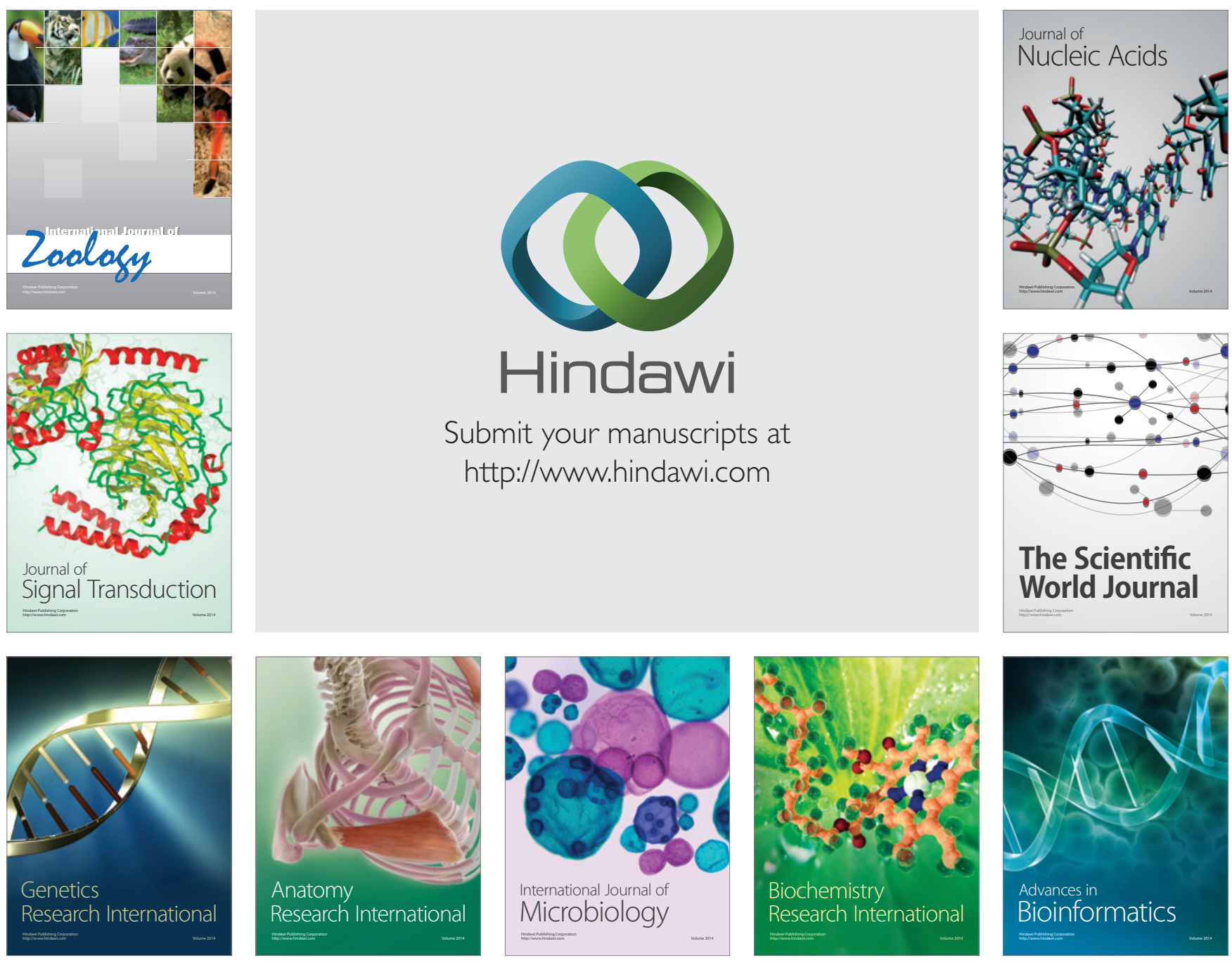

The Scientific World Journal
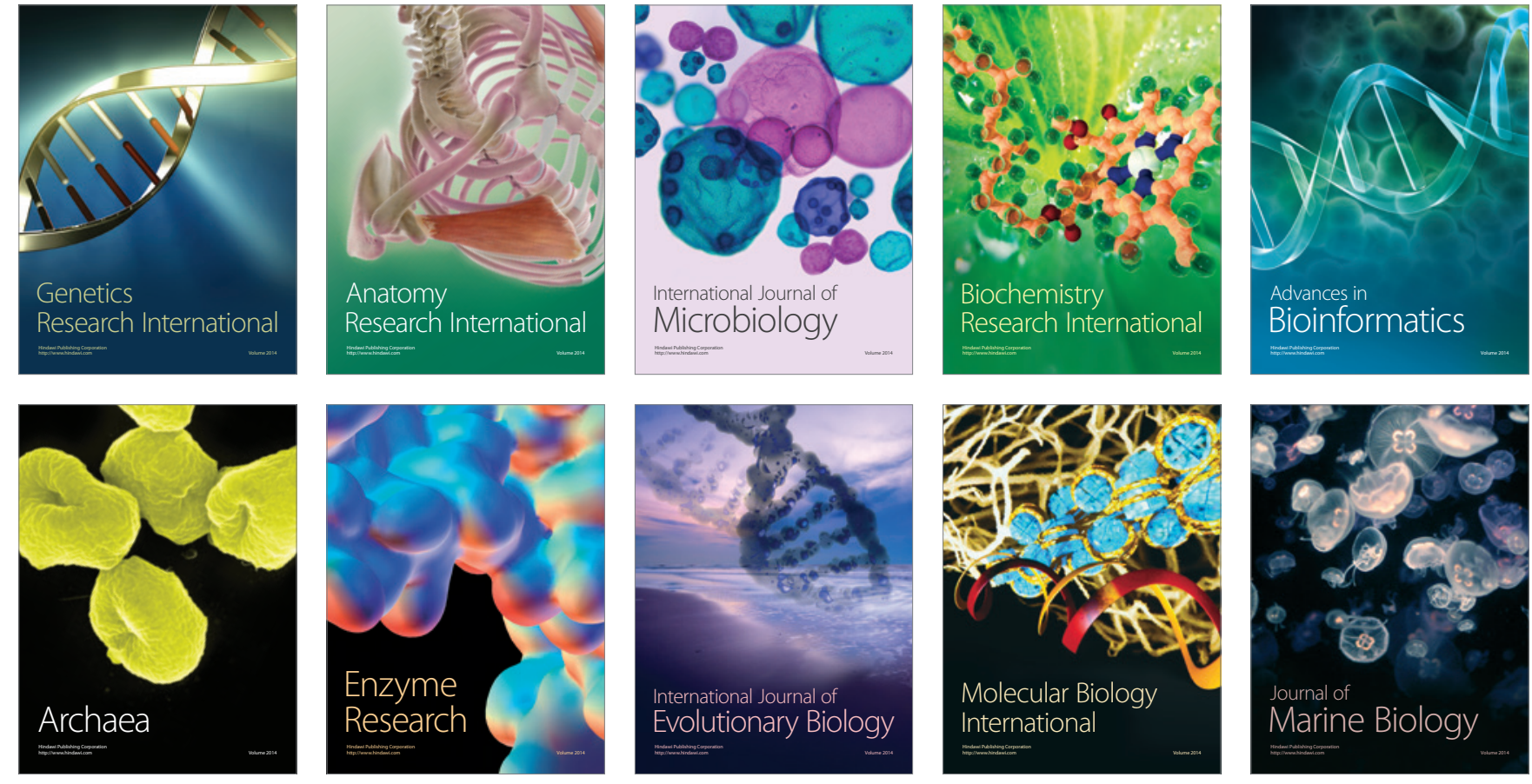